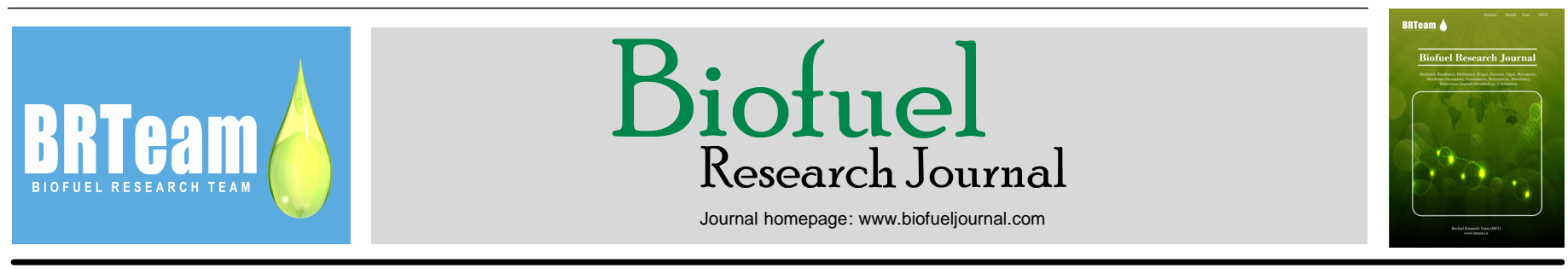

Editorial

\title{
Cellulose: a key polymer for a greener, healthier, and bio-based future
}

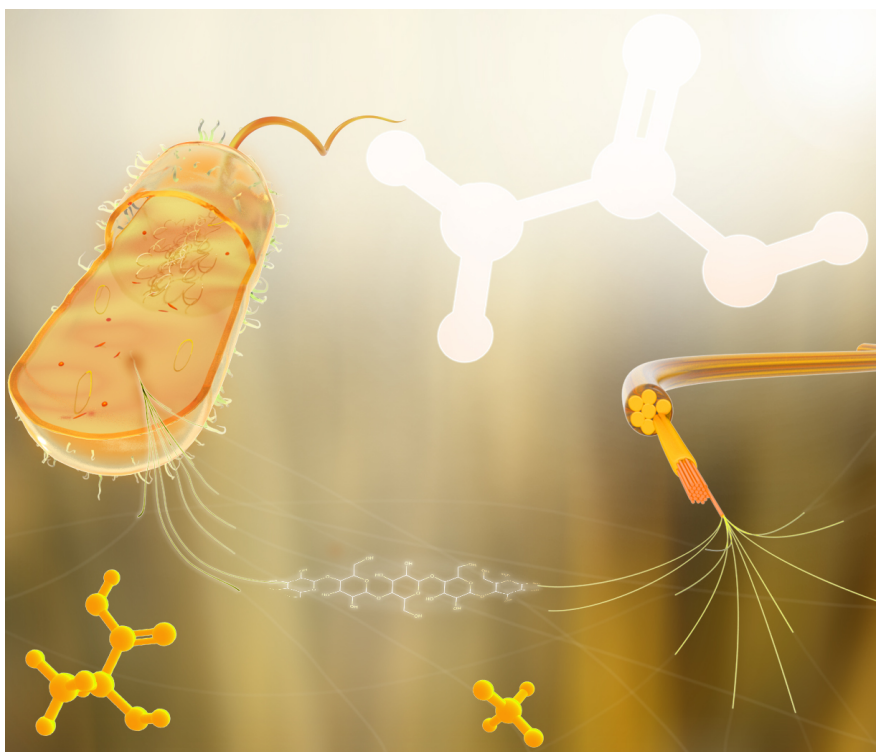

Moving to a more sustainable future based on the use of renewable resources and biomass wastes, saving energy, along with reduced $\mathrm{CO}_{2}$ emissions to the atmosphere is the goal of countries around the world. This is desperately needed due to the impacts of rapid economic development and population growth on resources, the environment, and global climate. The use of biomass as an energy source brings a number of advantages when compared with the use of fossil fuels, such as lower emissions of sulfur and other pollutants $\left(\mathrm{CO}, \mathrm{HC}\right.$, and $\mathrm{NO}_{\mathrm{x}}$ ) to the atmosphere, less contribution to the greenhouse effect, possibility of reusing and valorizing wastes, less energy dependence for the nations, etc.

Cellulose is the most abundant, inexpensive, and readily available natural polymer in the world. It is the dominant structural polysaccharide of plant cell walls (30-50 wt.\%) and is traditionally extracted from plants or their wastes for further use. One of the largest and well-known applications of cellulose is for the production of pulp and paper. However, there are other numerous possibilities for use of this natural polymer, mainly for obtaining products that could be used to replace the oil-derived ones, meeting the worldwide target of developing more sustainable processes for a greener and bio-based future. Ethanol, for example, is one of the most studied and interesting cellulosic biomass-based products due to the current incentives to produce and use biofuels for replacement of fossil-oil. Other energy carriers potentially produced for local usages are biomethane and biohydrogen. Alternative to energy carriers, chemicals production based on lignocellolusic waste fermentation is increasingly attracting attention. More specifically, organic acids (including lactic, citric, acetic, and succinic acids) as well as other chemicals like glycerol, sorbitol, hydroxymethylfurfural, etc., can also be produced from cellulose obtained from lignocellolusic wastes.

Cellulose recovery from wastewater treatment processes is another topic of interest which has attracted a great deal of attention recently leading to considerable investments. In wastewater treatment processes, sieving is a mechanical method usually applied to remove solid particles. A significant part of the sieved material removed during this step (approx. 40-50\%) consists of cellulose fibers, which mainly originates from toilet papers. This is a very significant amount taking into account that on average around $10 \mathrm{~kg}$ toilet paper is used per person each year. Every year 180.000 tons of toilet papers is flushed down the toilets of the Netherlands, for example; an amount equivalent to approx. 180.000 trees. Besides this huge amount of toilet papers, the cellulose fibers separated in the sieved material may also be derived from clothes, fruits, and vegetables. The possibility of recovering and adding value to these cellulosic fibers would increase the sustainability of wastewater treatment processes with the possibility of generating new products while requiring less energy for cleaning the water.

Although plants are the main source of cellulose, various bacteria are also capable of producing cellulose. Bacterial cellulose differs chemically from the cellulose produced by plants owing to its higher purity (i.e., no lignin and hemicelluloses) offering interesting properties when compared with plant cellulose such as higher water retention capacity, higher degree of polymerization, higher mechanical strength, and higher crystallinity. Due to these properties, bacterial cellulose has found potential applications in biomedical, food, cosmetic, and textile arenas. For instance, in tissue engineering, nanofibrillar structure of bacterial cellulose is known to form an ideal matrix assisting with the treatment of dermal lesions as well as in replacing skin, cartilage, bones, blood vessels, etc. It should be noted that the benefits of using these products are mainly associated with their biocompatibility and easy adhesion to the target tissue, as a consequence of their microfibrillar structure, transparency, and biocompatibility. Bacterial cellulose has also been found promising as support for drug release. From the food industry perspective, bacterial cellulose has been used for food packaging due to its fine network, biodegradability, and high water resistance. It has also been used as a thickening and stabilizing agent, and as a source of fibers in functional foods and drinks offering increased health benefits. Finally, an interesting emerging application of cellulose is in the production of nanocomposite materials with unique properties.

Overall, cellulose from renewable materials and biomass wastes, as well as cellulose produced by bacteria are expected to significantly contribute to the development of a greener and healthier future economy based on the production and use of more sustainable products and processes. Moreover, the integration of ligno-biofuel industry with the production of these value addedproducts could offer promises to increase the economic viability of this industry in the future.

Editors

Solange I. Mussatto Novo Nordisk Foundation Center for Biosustainability Technical University of Denmark, Denmark. Email Address: smussatto@biosustain.dtu.dk

Mark van Loosdrecht Department of Biotechnology Delft University of Technology, The Netherlands. Email Address: M.C.M.vanLoosdrecht@tudelft.nl 